\title{
Colorectal endoscopic submucosal dissection: patient selection and special considerations
}

This article was published in the following Dove Press journal:

Clinical and Experimental Gastroenterology

13 July 2017

Number of times this article has been viewed

\section{Andrew Emmanuel \\ Shraddha Gulati \\ Margaret Burt \\ Bu'Hussain Hayee \\ Amyn Haji}

King's Institute of Therapeutic Endoscopy, King's College Hospital, London, UK
Correspondence: Amyn Haji

King's Institute of Therapeutic

Endoscopy, King's College Hospital

NHS Foundation Trust, Denmark Hill,

SE5 9RS London, UK

Tel +4402032993268

Email amynhaji@nhs.net

\begin{abstract}
Endoscopic submucosal dissection (ESD) enables en bloc resection of large complex colorectal superficial neoplastic lesions, resulting in very low rates of local recurrence, highquality pathologic specimens for accurate histopathologic diagnosis and potentially curative treatment of early adenocarcinoma without resorting to major surgical resection. The safety and efficacy of the technique, which was pioneered in the upper gastrointestinal tract, has been established by the consistently impressive outcomes from expert centers in Japan and some other eastern countries. However, ESD is challenging to perform in the colorectum and there is a significant risk of complications, particularly in the early stages of the learning curve. Early studies from western centers raised concerns about the high complication rates, and the impressive results from Japanese centers were not replicated. As a result, many western endoscopists are skeptical about the role of ESD and few centers have incorporated the technique into their practice. Nevertheless, although the distribution of expertise, referral centers and modes of practice may differ in Japan and western countries, ESD has an important role and can be safely and effectively incorporated into western practice. Key to achieving this is meticulous lesion assessment and selection, appropriate referral to centers with the necessary expertise and experience and application of the appropriate technique individualized to the patient. This review discusses the advantages, risks and benefits of ESD to treat colorectal lesions and the importance of preprocedure lesion assessment and in vivo diagnosis and outlines a pragmatic rationale for appropriate lesion selection as well as the patient, technical and institutional factors that should be considered.
\end{abstract}

Keywords: endoscopic submucosal dissection, colorectal ESD, endoscopic resection

\section{Introduction}

Endoscopic submucosal dissection (ESD) allows organ-preserving, en bloc, curative resection of large superficial neoplastic lesions and cancers with early submucosal invasion in the colon and rectum. ESD was first developed to treat lesions in the upper gastrointestinal tract. ${ }^{1}$ However, in the colon and rectum, endoscopic mucosal resection (EMR), pioneered over 40 years ago and in established practice for several decades, was the mainstay of treatment as colorectal ESD was considered technically challenging compared to gastric or esophageal ESD because of the difficulties in scope stability and manipulation and a higher risk of perforation and fecal peritonitis due to the thin colonic wall. ${ }^{2-4}$ Nevertheless, following its established role in the upper gastrointestinal tract, ESD was first described in the colorectum in the late 1990s and there has since been a proliferation in its use..$^{5}$ In series involving several thousands of patients, it has been shown to achieve high rates of en bloc and curative resection 
of large lesions with low recurrence rates compared to EMR and is thought to have the added advantage of providing more accurate pathologic diagnosis and reducing the need for additional surgery. ${ }^{6-11}$

However, almost all of these results are obtained from large series from expert centers in Asia, primarily Japan. ${ }^{9}$ The adoption of ESD in western practice has been very limited because of its technical difficulty, steep learning curve and the difference in training opportunities compared to Japan because of the relative scarcity of early gastric and esophageal cancer. ${ }^{12-14}$ There are concerns about the difference in outcomes and adverse events in western compared to Japanese series, ${ }^{9,15-17}$ leading many western endoscopists to favor EMR as a safer, technically less demanding and more feasible universal strategy for tackling almost all suitable colorectal lesions. ${ }^{12,13,18,19}$

ESD, however, undoubtedly provides several advantages over EMR for appropriately selected patients, for example, where en bloc resection of lesions at high risk of containing submucosal invasion is essential. ${ }^{20}$ It is also a valuable technique in resecting lesions with profound submucosal fibrosis from previous resection or heavy manipulation, which is common in western practice. ${ }^{21}$ The patient population, referral patterns, case load for the relatively few experienced interventional colorectal endoscopists and lesion characteristics are likely to be substantially different from eastern practice. The key to safely and effectively incorporating ESD into western practice is the adoption of a pragmatic, lesionspecific approach using accurate preprocedure assessment and in vivo diagnosis to guide meticulous patient selection, as well as treatment by interventional endoscopists with expertise in the full range of endoscopic resection techniques.

In this review, we will consider the benefits and challenges of ESD in western practice and discuss the importance of appropriate patient selection and special patient, institutional and technical considerations when deciding the appropriateness of using the technique.

\section{Outcomes and advantages of colorectal ESD}

\section{En bloc resection}

Foremost among the suggested benefits of ESD is that it offers the possibility of en bloc resection of large lesions in the colon and rectum. Indeed, most other benefits of ESD, such as reduced recurrence, improved histopathologic diagnostic accuracy and potential curative treatment for early invasive cancers, stem from the ability to achieve en bloc resection using this technique.
There have been several systematic reviews and metaanalyses examining ESD, which have demonstrated en bloc resection rates using ESD of $88 \%-92 \%$, compared to $35 \%$ $63 \%$ for EMR. ${ }^{6-9,22,23}$ Although a randomized control trial comparing ESD and EMR is in progress, there are no published randomized control trials comparing the techniques. ${ }^{24}$ Nevertheless, these systematic reviews and meta-analyses include several thousands of patients and it is clear that very high rates of en bloc resection can be achieved. While en bloc resection using EMR is only consistently achieved for lesions $<2 \mathrm{~cm},{ }^{25} \mathrm{ESD}$ can achieve en bloc resection for much larger lesions, and successful en bloc resection of massive lesions over $10 \mathrm{~cm}$ has been reported. ${ }^{26,27}$ Furthermore, hybrid techniques using ESD to perform a circumferential mucosal incision with partial submucosal dissection, followed by EMR, can often be used where complete ESD is either too technically challenging or sufficient expertise is lacking to achieve en bloc resection in a greater proportion of lesions $>2 \mathrm{~cm}$ than would otherwise be possible with EMR alone. ${ }^{28,29}$

\section{Low recurrence rates}

As a result of these high rates of en bloc resection, few local recurrences are seen after ESD, despite the often large lesion size. A multicenter study found that, regardless of the technique employed, piecemeal resection was the most important risk factor for recurrence; also, a meta-analysis of risk factors for local recurrence found that piecemeal resection was the only independent risk factor for recurrence. ${ }^{30,31}$ Akintoye et al included several thousands of cases of ESD in a meta-analysis and found a pooled recurrence rate of only $1 \% .^{9}$ Other meta-analyses have consistently demonstrated rates of local recurrence after ESD of $0.7 \%-1.2 \%$, compared to $10.4 \%-12.7 \%$ after EMR. ${ }^{6,8,22,23}$

\section{Accurate diagnosis and curative resection of early adenocarcinoma}

En bloc resection to aid the accuracy of histopathologic diagnosis is of particular importance in the presence of adenocarcinoma. ${ }^{32-35}$ Piecemeal resection can make accurate assessment of the depth of invasion of an adenocarcinoma difficult, which could potentially lead to subsequent incorrect over- or undertreatment of a lesion. It has been suggested that inaccuracies in the assessment of depth of invasion due to piecemeal resection have led to invasive recurrences of adenocarcinoma, although there is, to date, no definitive evidence for this assertion. ${ }^{36}$ Aiding the accurate histopathologic diagnosis of specimens is one of the primary reasons for recommending ESD in guidelines from both Japan and 
Europe, and the types of lesion where this is particularly recommended will be discussed in further detail below. ${ }^{20,35,37}$ In addition, en bloc resection allows curative endoscopic resection of adenocarcinoma with early submucosal invasion, as lymph node metastases are rare in adenocarcinoma with only superficial submucosal invasion or invading $<1000$ $\mu \mathrm{m}$ from the muscularis mucosae. ${ }^{38,39}$ In fact, several series have demonstrated that, in the absence of high-risk histopathologic factors including lymphovascular invasion, poor differentiation or tumor budding, early colorectal cancer with only superficial submucosal invasion or invasion to a depth of $<1000 \mu \mathrm{m}$ is associated with a risk of lymph node metastases approaching $0 \% .{ }^{40-46}$ As a result, ESD is recommended where there is a risk of only superficial submucosal invasion and curative endoscopic resection may be possible. ${ }^{35}$ In the absence of any high-risk histopathologic features, ESD has been shown to provide excellent oncologic results and a potentially better safety profile compared to standard surgical segmental resection. ${ }^{47}$

However, it is worth noting that EMR has also been used for many years to effectively treat early colorectal cancers without high-risk features and that, despite the sound scientific rationale behind recommending en bloc resection using ESD to aid diagnosis and curative resection, no convincing evidence of its benefit over EMR in oncologic outcomes has been published. ${ }^{44-46}$

\section{Disadvantages of ESD}

Colorectal ESD is a technically demanding modality for endoscopic resection, with an increased risk of adverse events as a result of difficulties achieving scope stability due to colonic looping; peristalsis, flexions and mucosal folds making manipulation of the knife challenging, the thin colonic wall allowing little margin of error during dissection and the risk of peritonitis from any perforation. ${ }^{4,9,48}$

\section{Complications}

One of the primary concerns about ESD has been the increased risk of perforation compared to EMR. Even in the expert hands of experienced Japanese endoscopists, initial case series of ESD reported relatively high perforation rates with early experience of $\sim 10 \%-12 \%{ }^{49-51}$

However, several points about the risk of perforation during ESD are worth noting. First, the risk appears to significantly reduce with experience, with one series demonstrating a reduction in perforations from $12 \%$ in its first 100 cases to $2 \%$ in the subsequent 100 cases. ${ }^{51}$ Large series of colorectal ESD suggest that the perforation rate in the hands of experienced practitioners is now in the range of $3.1 \%-5.6 \% .^{9-11,52-57}$ Second, despite an apparently higher perforation rate, the overwhelming majority of cases are recognized immediately and successfully managed by closing the defect with endoscopic clips or with conservative management and only a small fraction require surgery. ${ }^{10,11,52,53}$ One caveat to this observation is that, although these patients avoided surgery, there is very little reporting in these studies of any subsequent outcomes such as delayed recovery, longer hospital stay, increased costs or antibiotic requirements. Third, comparisons of perforation rates between ESD and EMR are difficult due to differences in important factors such as lesion size between different cohorts.

Although meta-analyses confirm that colorectal ESD is associated with a significantly greater risk of perforation with rates ranging from $4.8 \%$ to $5.7 \%$ for ESD compared to $0.9 \%-1.4 \%$ for EMR, these are almost exclusively based on retrospective studies; also, lesions resected using ESD were larger than those resected using EMR and these studies do not report other details of the lesions that may have affected perforation. ${ }^{6-8,22,23}$

Significant bleeding is a relatively infrequent complication of ESD, and it appears that the risk of bleeding is similar regardless of the resection technique. Although definitions of significant bleeding vary between studies, it reportedly occurs in $0.5 \%-2.75 \%$ of cases. . $^{911,52,54,56}$

\section{Procedure time}

ESD is a technically challenging procedure, which is reflected in the significantly longer procedure time compared to EMR. ${ }^{6-8,36,58}$ This has implications not only for institutions' service provision, but also for patients who usually have the procedure performed under conscious sedation. Data recording patient experience of ESD compared to other procedures are lacking.

\section{Hospital admission}

In expert centers in Japan, patients undergoing ESD are usually admitted to hospital for a significant period of time. ${ }^{59,60}$ Even within a special clinical pathway designed to reduce hospital stay, the mean length of stay was 5 days. ${ }^{61}$ By contrast, EMR is usually performed as a day case procedure. ${ }^{62}$

\section{Availability of expertise and opportunities for training}

The availability of expert endoscopists with the necessary experience in ESD is of particular relevance in western practice. Related to this is the added difficulty of ensuring 
appropriate training opportunities in a western setting. ${ }^{63}$ In Japan, well-defined training pathways have been established, which begin with technically easier and safer procedures in the stomach, progressing to the esophagus and finally to the rectum and colon. ${ }^{64-66}$ Suitable upper gastrointestinal lesions are far less common in the west. These issues, together with concerns about the impact on interventional endoscopy services due to the added length of procedure and risk of complications, have led to slow uptake of ESD in western practice. Reluctance to adopt ESD was compounded by some early western series on colorectal ESD reporting significant and concerning complication rates, ${ }^{16,67,68}$ although, as noted above, there appears to be a clear learning curve with reduction of complications with increasing experience, which has also been demonstrated in a western setting. ${ }^{15}$ Emerging evidence from Europe suggests comparable en bloc resection and perforation rates to eastern practice. ${ }^{69,70}$

\section{Indications for ESD}

Although several international authorities have published guidance on endoscopic resection in the colorectum, the Japanese Gastroenterological Society and several expert centers in Japan are the only authorities to define clear recommendations for colorectal ESD. These criteria may be applicable in Japan where the necessary skills and institutional experience exist, but their relevance in western practice is less clear. Nevertheless, they provide a useful starting point when considering appropriate patient and lesion selection for ESD. In most guidelines, ESD is recommended based on the size of the lesion (and, therefore, the risks of piecemeal resection) and the risk of adenocarcinoma.

\section{Risk of invasive adenocarcinoma}

As the primary advantage of ESD is en bloc resection of lesions allowing accurate diagnosis and potentially curative resection of adenocarcinoma, one of the central tenants in selecting suitable lesions for ESD is that the risk of a large lesion containing adenocarcinoma varies according to its morphology and surface (pit) pattern. Lesions $<2 \mathrm{~cm}$ can be resected en bloc using EMR, and so ESD is primarily of relevance for lesions $>2 \mathrm{~cm}$ which are most commonly laterally spreading tumors (LST). Figure 1 shows the different morphological subtypes of LST. The incidence of adenocarcinoma in LST granular (LST G) homogenous type lesions is low, whereas it is higher in LST G mixed-nodular type lesions and, when present, tends occur under a large nodule. The incidence is highest in LST nongranular (LST NG) type lesions, particularly the pseudodepressed type, and also tends
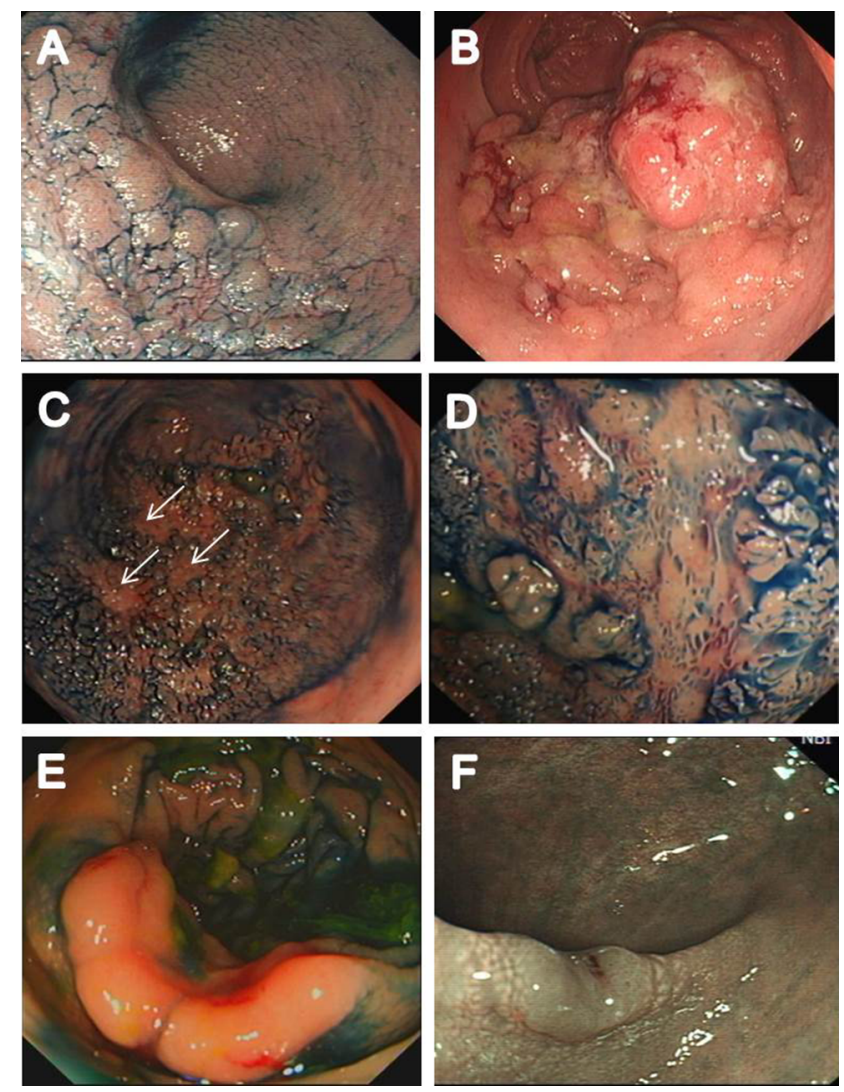

Figure I Different morphological subtypes of LST.

Notes: (A) LST granular homogeneous; (B) LST granular mixed-nodular; (C, D) LST granular homogeneous with several areas of profound submucosal scarring/ fibrosis (white arrows) from previous attempts at resection before referral; (E, F) LST nongranular pseudodepressed type.

Abbreviation: LST, laterally spreading tumors.

to be multifocal in these lesions..$^{33,71,72}$ In addition, the risk of submucosal invasion can be accurately predicted using magnification chromoendoscopy to determine the presence of type $\mathrm{V}$ pit pattern as well as other image enhancement techniques such as narrow band imaging (NBI). ${ }^{73-77}$

\section{Risk of recurrence}

ESD may be selected based on lesion size. The risk of recurrence is consistently related to the size of the lesion and piecemeal resection in studies, and en bloc resection is not consistently achieved for lesions $>2 \mathrm{~cm}$ using EMR. ${ }^{25,31}$

\section{Guidelines for selecting ESD}

The Japanese Gastroenterological Society and expert centers in Japan, therefore, recommend ESD for lesions where en bloc resection is necessary and would be difficult to achieve with EMR, including LST NG larger than $2 \mathrm{~cm}$, LST G larger than $3 \mathrm{~cm}$ (especially mixed-nodular type), Vi pit pattern or suspicion of only superficial submucosal invasion, recurrent lesions and lesions with submucosal fibrosis. 
Other international guidance, although adhering to similar principles, is less definitive owing largely to the paucity of expert centers and endoscopists performing ESD in western practice. ${ }^{20,37,78}$ Guidance from societies in the UK and Europe both not only acknowledge the potential role of ESD in en bloc resection where adenocarcinoma is suspected, but also note that piecemeal EMR is safe and highly effective for the majority of large colorectal superficial neoplastic lesions. ${ }^{20,37}$

\section{Controversies regarding the indications for ESD}

A liberal interpretation of the indications for ESD could include any lesion with a risk of harboring adenocarcinoma or where the risk of recurrence is significant and this means that in expert centers in Japan, where the expertise exists and the case load allows, many large colorectal lesions are resected using ESD. ${ }^{79}$ However, some western endoscopists question the value of ESD for the majority of colorectal superficial neoplastic lesions. Aside from the lack of opportunities for training and gaining sufficient experience of ESD already discussed, they take the view that EMR and piecemeal EMR are highly effective and safe procedures for resecting large superficial colorectal lesions in over $90 \%$ of patients. Although the recurrence rate may be higher than after en bloc resection by ESD, this is successfully treated by EMR in most cases and is a low-risk and relatively simple procedure which does not usually require hospital admission. ${ }^{62,80}$ In addition, EMR is widely practiced and the necessary skills and experience are easier to attain. ${ }^{37}$

Some argue that the additional benefit of performing ESD is minimal for most lesions as evidenced by the fact that few lesions contain adenocarcinoma and, for those resected en bloc by ESD, approximately half require surgery as they contain high-risk features. ${ }^{11,13,14,19}$ This leaves only a fraction of patients potentially receiving curative resection by ESD, and the costs and resource burden may not justify the universal use of ESD for large lesions, especially where the benefit is small, such as lesions in the right colon when the morbidity associated with laparoscopy is minimal. ${ }^{12,19,81}$

Some have argued that there is no evidence that fewer patients require surgery after treatment with ESD compared to EMR, despite the claim that ESD may afford curative resection to more patients and reduce recurrence. ${ }^{82}$ There are several limitations in the studies comparing techniques, but in many, the requirement for surgery following ESD is either similar or more frequent compared to EMR ${ }^{8,23}$ Some authors feel it is safest to generally recommend surgery when adenocarcinoma is found and, as a result, EMR is sufficient. ${ }^{81}$
However, even authors who note the limited uptake of ESD in the west or question the extent to which ESD should be used generally agree that there is an important role for the technique in resecting particularly high-risk lesions en bloc or tackling difficult fibrotic lesions, and it is likely that it will be increasingly employed in western practice in the future. . $^{18,19,79}$

\section{Patient selection}

Given the advantages and efficacy of both ESD and EMR, it is necessary to arrive at a pragmatic approach to patient and lesion selection which will allow the best technique to be delivered to the right patient, as well as allow the most effective use of ESD within the resources available in the majority of centers.

Figure 2 shows the approach we have adopted in selecting lesions for ESD. Meticulous assessment prior to resection in order to make an accurate endoscopic prediction of the risk of invasive adenocarcinoma is of paramount importance in selecting the most appropriate resection technique. Magnification chromoendoscopy and NBI are invaluable in this decision-making process. ${ }^{35,71,75,76}$ If the expertise is available, colonoscopic ultrasound may also be used to supplement this process in lesions where type $\mathrm{Vi}$ pit is discovered or where the risk of submucosal invasion is high, such as LST NG or LST G mixed-nodular lesions, in an attempt to exclude deep invasion before resection is attempted. ${ }^{83-85}$ Endoscopic resection should not be considered for lesions which obviously have deeply invasive adenocarcinoma, for example, lesions displaying Vn pit pattern or where colonoscopic ultrasound suggests deep invasion.

\section{Definitive indications for en bloc resection}

En bloc resection should be performed where there is a high risk of adenocarcinoma with superficial invasion. This includes LST NG lesions, particularly pseudodepressed type, and lesions displaying Vi pit. All such lesions $>2 \mathrm{~cm}$ should be resected using ESD, although ESD should also be used for smaller LST NG lesions where en bloc resection by EMR may be compromised by submucosal fibrosis. If ESD is not performed locally, then these patients should be referred to a center where the expertise is available.

\section{Lesions for which ESD is preferable}

Lesions with a significant risk of harboring invasive adenocarcinoma should be resected using ESD where possible. This includes LST G mixed-nodular lesions. However, en bloc resection using ESD may not be possible due to factors such as extreme lesion size, patient frailty and comorbidity 


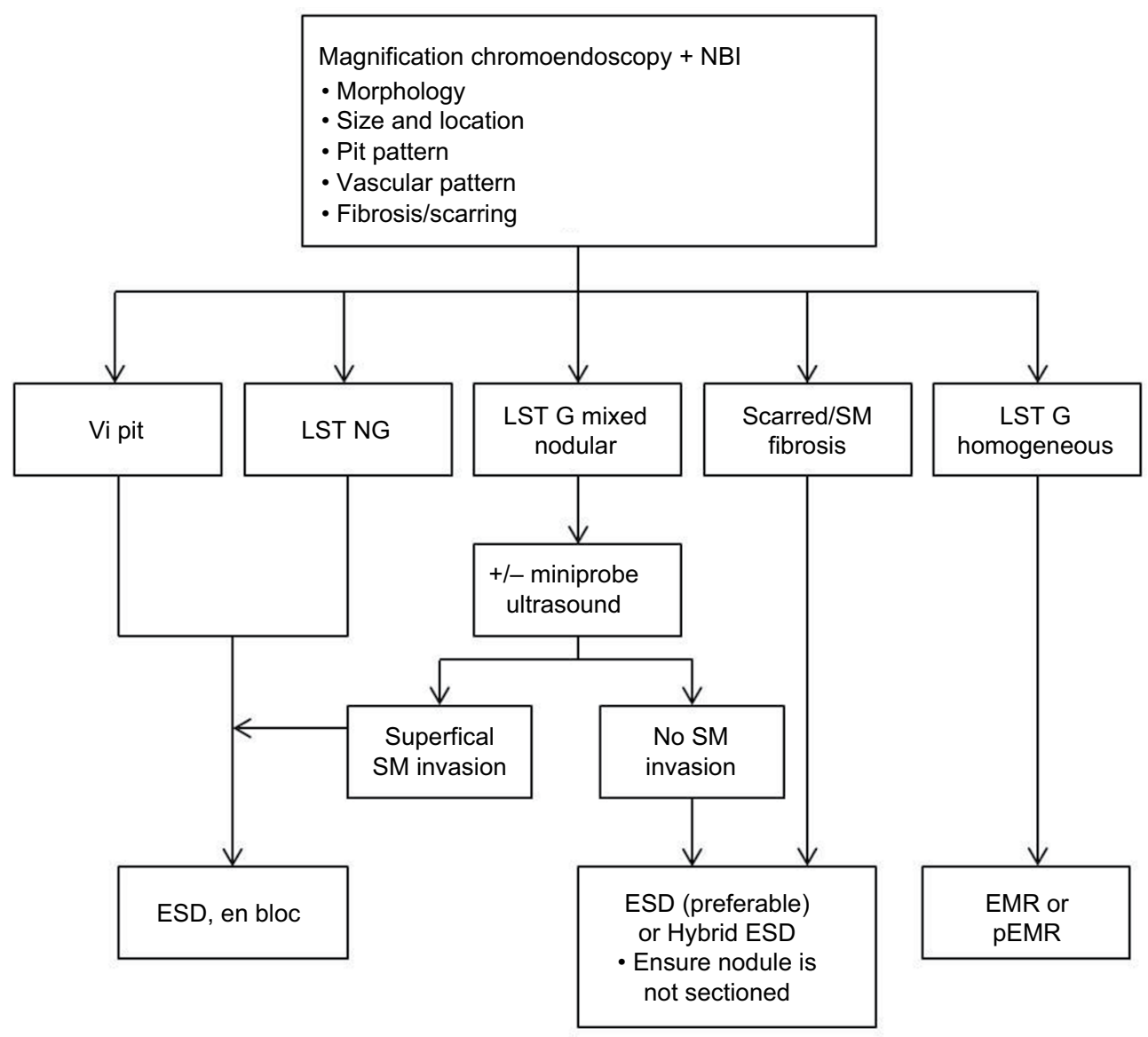

Figure 2 Process of lesion-specific selection of resection technique at King's College Hospital.

Abbreviations: EMR, endoscopic mucosal resection; ESD, endoscopic submucosal dissection; LST, laterally spreading tumors; LST G, laterally spreading tumors granular; LST NG, laterally spreading tumors nongranular; NBI, narrow band imaging; pEMR, piecemeal endoscopic mucosal resection; SM, submucosal.

precluding a lengthy procedure, deeply scarred lesions from previous attempts at resection or a lack of suitable expertise in ESD. When invasive adenocarcinoma occurs in such lesions, it is almost invariably present under the largest dominant nodule or under depressed areas (Figure 1B). ${ }^{33,71,76}$ Therefore, at a minimum, the resection strategy for these lesions should be removal of these areas in one piece to avoid sectioning an area of adenocarcinoma before piecemeal resection to complete the removal of the remaining granular portion of the lesion. ${ }^{10,33,35,48,71,86,87}$

\section{Lesions for which ESD is not essential}

Although en bloc resection is always preferable, the practical realities of advanced interventional endoscopy, particularly outside of Japan, are that piecemeal EMR is the most viable strategy for safe and effective resection in some patients. LST $\mathrm{G}$ homogenous lesions have a very low incidence of unrecognized adenocarcinoma, even at a large size, and therefore can be resected using piecemeal EMR. ${ }^{10,33}$ Lesions of any morphology $<2 \mathrm{~cm}$ can, in principle, be resected en bloc using EMR, although if there is any suspicion of superficial submucosal invasion, we would recommend considering ESD even for these smaller lesions because it allows consistent en bloc resection and also enables accurate submucosal dissection under vision, ensuring R0 resection and a high-quality pathologic specimen. Figure 3 shows examples of appropriate selection of resection technique specific to the patient and lesion characteristics.

\section{Lesions for which ESD is a valuable technique}

There are situations for which ESD is a useful technique to allow effective treatment of a benign colorectal lesion, but where it is not required specifically for en bloc resection.

Lesions which are deeply scarred as a result of recurrence after previous resection present a particular challenge (Figure 1C and D). Although these can be effectively treated by EMR, especially if diminutive in size, many larger recurrent or residual lesions are resistant to submucosal lifting and snare capture. ${ }^{62,80,88}$ ESD may be the only effective resection strategy for these, either as the sole modality or as part of a 

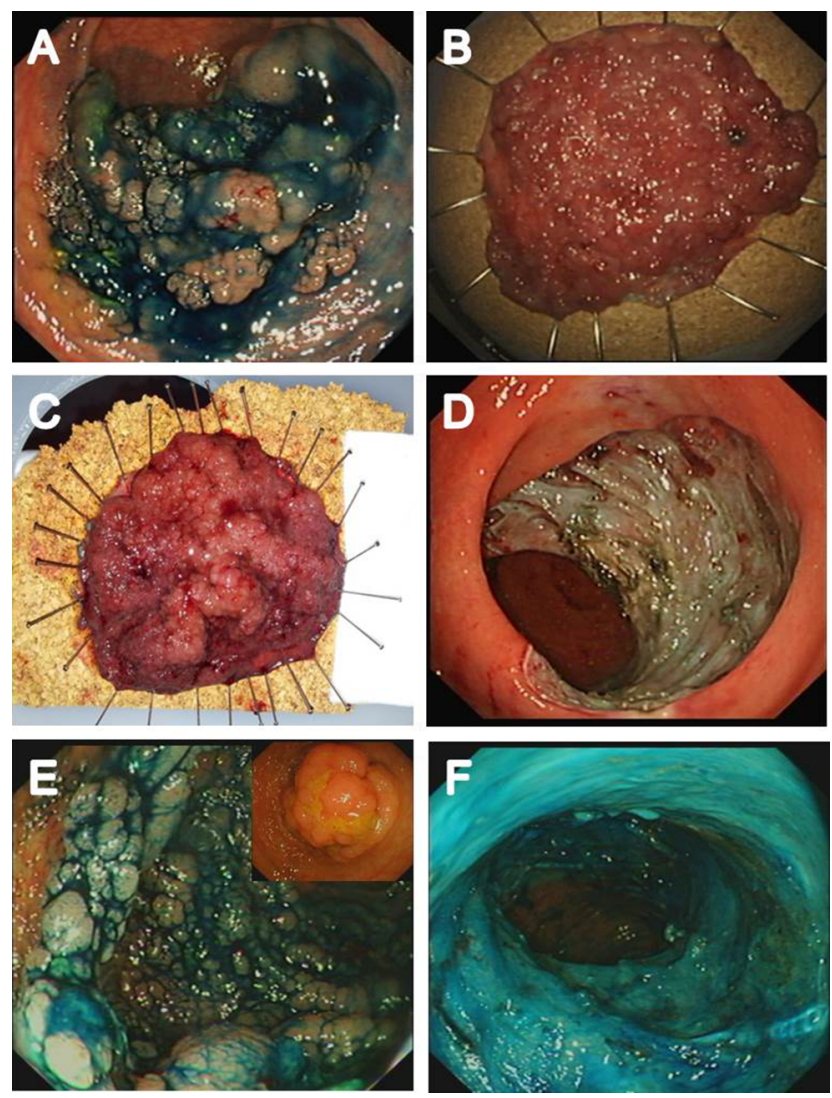

Figure 3 Examples of appropriate selection of resection technique.

Notes: (A-D) En bloc resection of these 8 and $10 \mathrm{~cm}$ LST granular mixednodular lesions is the procedure of choice to aid accurate histopathologic assessment. However, hybrid ESD or pEMR is more appropriate for this $16 \mathrm{~cm}$ fully circumferential lesion in a 92 -year-old patient $(\mathbf{E}, \mathbf{F})$ unlikely to tolerate a lengthy ESD. Significant nodular components ( $E$, inset) should be resected in one piece and not sectioned. This was successfully resected as a day case procedure with minimal sedation, with no recurrence at the last follow-up.

Abbreviations: ESD, endoscopic submucosal dissection; LST, laterally spreading tumors; pEMR, piecemeal endoscopic mucosal resection.

hybrid technique. Several small series have demonstrated that ESD can be used to achieve safe resection of recurrent lesions with impressive en bloc resection rates, or as part of a hybrid procedure to enable effective snare capture ${ }^{89-93}$ However, significant submucosal fibrosis has been consistently identified as a risk factor for recurrence and perforation during ESD, as well as adding to the technical difficulty of the procedure, and therefore, the use of ESD for these particularly challenging lesions should be reserved for interventional endoscopists with sufficient experience. ${ }^{94-96}$

Lesions extending to the anorectum and dentate line are especially challenging to resect with endoscopic techniques as a result of difficult access and visualization and pain due to the somatic sensory innervation, and there may be a lower threshold for surgical management in these cases. ${ }^{97,98} \mathrm{ESD}$ is a safe and highly effective technique for such lesions, even in the presence of hemorrhoids, with minimal risk of bleeding and very low risk of recurrence. ${ }^{98-100}$

\section{Technical, institutional and patient considerations}

Detailed discussion of the endosurgical knives and equipment available for performing ESD is beyond the scope of this review and has been detailed elsewhere; however, the development of certain techniques has greatly assisted successful ESD for large tumors. ${ }^{32,101,102}$

\section{Dissection techniques - pocket-creation method}

The technique for colorectal ESD has evolved to one in which a partial mucosal incision is initially performed followed by variable amounts of submucosal dissection instead of an initial circumferential mucosal incision, as this maintains mucosal tension which assists insertion of the distal attachment and prevents leakage of injection fluid. This was further developed into the pocket-creation method in which, following a minimal partial mucosal incision, a large submucosal pocket is created under the lesion before completing the mucosal incision circumferentially. ${ }^{103-105}$ This has the advantage of maintaining a thick submucosal layer under the tumor, resulting in a high-quality pathologic specimen. Also, insertion of the distal attachment into the submucosal pocket results in the tip being spontaneously fixed and, therefore, synchronized with breathing or heart beats, thus maintaining the tip of the knife at a stable distance from the submucosa. ${ }^{103,104} \mathrm{~A}$ further modification of this technique for lesions complicated by submucosal fibrosis is the formation of multiple pockets which meet at the area of fibrosis, allowing accurate identification of the muscle layer and precise dissection of the muscle. ${ }^{105}$

\section{Retraction techniques}

One of the difficulties with ESD is maintaining adequate traction. Patient position change to make optimal use of gravity is the most commonly employed method. ${ }^{106,107}$ A variety of innovations have been described to assist with traction, most involving endoscopic clips. ${ }^{108}$ One of the simplest and most cost-effective is the clip with line method. ${ }^{107,109}$ An endoscopic hemoclip is inserted into the colonoscope, a length of dental floss or silk is tied to one arm, the clip is then withdrawn back into the endoscope which is reinserted, and the clip is deployed onto the mucosal flap where traction is required. Counter traction is then achieved by pulling the dental floss or silk gently or applying a light weight to the opposite end. Various directions of counter traction can be achieved using modifications of the technique by creating a pulley effect using a second clip to "capture" the line and then fixing this second clip to the opposite side of the lumen. The dental floss 
is then drawn through this second clip, altering the direction of pull on the first clip. ${ }^{107}$

Another simple method is the clip-flap method in which clips are applied to the incised mucosal edge soon after mucosal incision and these act to assist gravity in lifting the mucosal edge, improving visualization of the submucosal plane to allow insertion of the distal attachment. ${ }^{101}$

Several other techniques have been described using additional endoscopes, external forceps or novel devices, but have not been widely applied, especially in the colorectum. ${ }^{110-112}$

\section{Institutional factors}

In order to safely and effectively incorporate ESD into an advanced interventional endoscopy practice, an adequate case load is essential. It has been demonstrated that complication rates for colorectal ESD are significantly lower in institutions performing a high volume of procedures. ${ }^{11}$ Clearly, it is not appropriate for every colonoscopist to attempt to perform ESD or, indeed, for every institution to offer ESD. Rather, it should be carried out by experienced practitioners in central referral hospitals to maintain the necessary experience which should translate into effective treatment. ${ }^{113}$

It may be useful, particularly in western practice, to introduce a complex polyp multidisciplinary meeting to ensure the correct treatment is given to patients in environments where surgery is often still performed for benign colorectal lesions and also to assist in correct decision making with regard to the resection technique or the need for referral. ${ }^{37,114}$

Effective models for ESD training in the west need to be established and validated. Various training pathways have been proposed involving the use of porcine models, a period of observation of Japanese experts and progressive use of the technique beginning in the rectum and progressing into the colon, as safety and competence are proven, preferably under the supervision of an expert. ${ }^{68,115-118}$ It is difficult to determine the exact learning curve for colorectal ESD as most studies involve endoscopists already experienced in upper gastrointestinal ESD. However, training in ESD is feasible without significant prior experience of upper gastrointestinal ESD. ${ }^{119,120}$

\section{Patient considerations}

It is important that the correct treatment is offered on an individual basis to patients. ESD may be indicated on the basis of specific lesion characteristics, but it may not be the most suitable treatment for the patient. Guidelines across nations are consistent in stating that the risks and benefits of a treatment should be carefully considered for each patient, especially the elderly. ${ }^{35,37}$ Elderly frail patients may be illequipped to withstand a lengthy procedure with the medications for conscious sedation which may be required for ESD.

\section{Conclusion}

A large body of evidence from Japan and other eastern expert centers, and emerging evidence from some western centers, has demonstrated that ESD is a highly effective technique to achieve en bloc resection of large colorectal superficial neoplastic lesions, allowing accurate histopathologic diagnosis and staging of adenocarcinoma and offering potentially curative organ-preserving, minimally invasive treatment for early cancer. With the appropriate expertise and experience, this can be achieved with minimal morbidity. However, accurate preprocedure assessment and in vivo diagnosis to aid appropriate lesion selection are essential to ensure the correct technique is offered to the patient, for which magnification endoscopy is an invaluable tool. There are substantial differences in training opportunities, referral patterns, knowledge among diagnostic endoscopists and modes of practice between the east and west, but ESD has been successfully introduced into some western referral centers and appropriate referral to such centers together with careful lesion and patient selection will maintain high-quality outcomes.

\section{Disclosure}

The authors report no conflicts of interest in this work.

\section{References}

1. Hirao M, Masuda K, Asanuma T, et al. Endoscopic resection of early gastric cancer and other tumors with local injection of hypertonic saline-epinephrine. Gastrointest Endosc. 1988;34(3):264-269.

2. Deyhle P, Largiadèr F, Jenny S, Fumagalli I. A method for endoscopic electroresection of sessile colonic polyps. Endoscopy. 1973;5(01):38-40

3. Yokota T, Sugihara K, Yoshida S. Endoscopic mucosal resection for colorectal neoplastic lesions. Dis Colon Rectum. 1994;37(11):1108-1111.

4. Lai LH, Chan FK. Endoscopic submucosal dissection for colonic lesions: why and how should we do it? J Dig Dis. 2011;12(4):229-233.

5. Gotoda T, Kondo H, Ono H, et al. A new endoscopic mucosal resection procedure using an insulation-tipped electrosurgical knife for rectal flat lesions: report of two cases. Gastrointest Endosc. 1999;50(4):560-563.

6. Wang J, Zhang XH, Ge J, Yang CM, Liu JY, Zhao SL. Endoscopic submucosal dissection versus endoscopic mucosal resection for colorectal tumors: a meta-analysis. World $J$ Gastroenterol. 2014;20(25):8282-8287.

7. Zhang HP, Wu W, Yang S, Shang J, Lin J. The efficacy and safety of endoscopic submucosal dissection compared with endoscopic mucosal resection for colorectal tumors: a meta-analysis. Int J Colorectal Dis. 2016;31(3):791-793.

8. Fujiya M, Tanaka K, Dokoshi T, et al. Efficacy and adverse events of EMR and endoscopic submucosal dissection for the treatment of colon neoplasms: a meta-analysis of studies comparing EMR and endoscopic submucosal dissection. Gastrointest Endosc. 2015;81(3):583-595. 
9. Akintoye E, Kumar N, Aihara H, Nas H, Thompson CC. Colorectal endoscopic submucosal dissection: a systematic review and metaanalysis. Endosc Int Open. 2016;4(10):E1030-E1044.

10. Saito Y, Sakamoto T, Fukunaga S, et al. Endoscopic submucosal dissection (ESD) for colorectal tumors. Dig Endosc. 2009;21 (Suppl 1): S7-S12.

11. Saito Y, Uraoka T, Yamaguchi Y, et al. A prospective, multicenter study of 1111 colorectal endoscopic submucosal dissections (with video). Gastrointest Endosc. 2010;72(6):1217-1225.

12. Holmes I, Friedland S. Endoscopic mucosal resection versus endoscopic submucosal dissection for large polyps: a western colonoscopist's view. Clin Endosc. 2016;49(5):454-456.

13. Bourke M. Current status of colonic endoscopic mucosal resection in the west and the interface with endoscopic submucosal dissection Dig Endosc. 2009;21 (Suppl 1):S22-S27.

14. Marín-Gabriel JC, Fernández-Esparrach G, Díaz-Tasende J, Herreros de Tejada A. Colorectal endoscopic submucosal dissection from a Western perspective: Today's promises and future challenges. World J Gastrointest Endosc. 2016;8(2):40-55.

15. Probst A, Golger D, Anthuber M, Märkl B, Messmann H. Endoscopic submucosal dissection in large sessile lesions of the rectosigmoid: learning curve in a European center. Endoscopy. 2012;44(7):660-667.

16. Farhat S, Chaussade S, Ponchon T, et al. Endoscopic submucosal dissection in a European setting. A multi-institutional report of a technique in development. Endoscopy. 2011;43(8):664-670.

17. Fuccio L, Hassan C, Ponchon T, et al. Clinical outcomes after endoscopic submucosal dissection for colorectal neoplasia: a systematic review and meta-analysis. Gastrointest Endosc. Epub 2017 Feb 28.

18. Saunders BP, Tsiamoulos ZP. Endoscopic mucosal resection and endoscopic submucosal dissection of large colonic polyps. Nat Rev Gastroenterol Hepatol. 2016;13(8):486-496.

19. Burgess NG, Bourke MJ. Endoscopic resection of colorectal lesions: The narrowing divide between East and West. Dig Endosc. 2016;28(3):296-305.

20. Pimentel-Nunes P, Dinis-Ribeiro M, Ponchon T, et al. Endoscopic submucosal dissection: European Society of Gastrointestinal Endoscopy (ESGE) Guideline. Endoscopy. 2015;47(9):829-854.

21. Kim HG, Thosani N, Banerjee S, Chen A, Friedland S. Effect of prior biopsy sampling, tattoo placement, and snare sampling on endoscopic resection of large nonpedunculated colorectal lesions. Gastrointest Endosc. 2015;81(1):204-213.

22. De Ceglie A, Hassan C, Mangiavillano B, et al. Endoscopic mucosal resection and endoscopic submucosal dissection for colorectal lesions: a systematic review. Crit Rev Oncol Hematol. 2016;104:138-155.

23. Arezzo A, Passera R, Marchese N, Galloro G, Manta R, Cirocchi R. Systematic review and meta-analysis of endoscopic submucosal dissection versus endoscopic mucosal resection for colorectal lesions. United European Gastroenterol J. 2016;4(1):18-29.

24. Backes Y, Moons LMG, van Bergeijk JD, et al. Endoscopic mucosal resection (EMR) versus endoscopic submucosal dissection (ESD) for resection of large distal non-pedunculated colorectal adenomas (MATILDA-trial): rationale and design of a multicenter randomized clinical trial. BMC Gastroenterol. 2016;16(1):56.

25. Kim HH, Kim JH, Park SJ, Park MI, Moon W. Risk factors for incomplete resection and complications in endoscopic mucosal resection for lateral spreading tumors. Dig Endosc. 2012;24(4):259-266.

26. Jung DH, Youn YH, Kim JH, Park H. Endoscopic submucosal dissection for colorectal lateral spreading tumors larger than $10 \mathrm{~cm}$ : is it feasible? Gastrointest Endosc. 2015;81(3):614-620.

27. Antillon MR, Bartalos CR, Miller ML, Diaz-Arias AA, Ibdah JA, Marshall JB. En bloc endoscopic submucosal dissection of a 14-cm laterally spreading adenoma of the rectum with involvement to the anal canal: expanding the frontiers of endoscopic surgery (with video). Gastrointest Endosc. 2008;67(2):332-337.

28. Hong YM, Kim HW, Park SB, Choi CW, Kang DH. Endoscopic mucosal resection with circumferential incision for the treatment of large sessile polyps and laterally spreading tumors of the colorectum. Clin Endosc. 2015;48(1):52-58.
29. Bae JH, Yang DH, Lee S, et al. Optimized hybrid endoscopic submucosal dissection for colorectal tumors: a randomized controlled trial. Gastrointest Endosc. 2016;83(3):584-592.

30. Oka S, Tanaka S, Saito Y, et al. Local recurrence after endoscopic resection for large colorectal neoplasia: a multicenter prospective study in Japan. Am J Gastroenterol. 2015;110(5):697-707.

31. Belderbos TD, Leenders M, Moons LM, Siersema PD. Local recurrence after endoscopic mucosal resection of nonpedunculated colorectal lesions: systematic review and meta-analysis. Endoscopy. 2014;46(5):388-402.

32. Bhatt A, Abe S, Kumaravel A, Vargo J, Saito Y. Indications and Techniques for Endoscopic Submucosal Dissection. Am J Gastroenterol. 2015;110(6):784-791.

33. Oka S, Tanaka S, Kanao H, Oba S, Chayama K. Therapeutic strategy for colorectal laterally spreading tumor. Dig Endosc. 2009;21 (Suppl 1): S43-S46.

34. Takeuchi Y, Ohta T, Matsui F, Nagai K, Uedo N. Indication, strategy and outcomes of endoscopic submucosal dissection for colorectal neoplasm. Dig Endosc. 2012;24 (Suppl 1):100-104.

35. Tanaka S, Kashida H, Saito Y, et al. JGES guidelines for colorectal endoscopic submucosal dissection/endoscopic mucosal resection. Dig Endosc. 2015;27(4):417-434.

36. Saito Y, Fukuzawa M, Matsuda T, et al. Clinical outcome of endoscopic submucosal dissection versus endoscopic mucosal resection of large colorectal tumors as determined by curative resection. Surg Endosc. 2010;24(2):343-352.

37. Rutter MD, Chattree A, Barbour JA, et al. British Society of Gastroenterology/Association of Coloproctologists of Great Britain and Ireland guidelines for the management of large non-pedunculated colorectal polyps. Gut. 2015;64(12):1847-1873.

38. Beaton C, Twine CP, Williams GL, Radcliffe AG. Systematic review and meta-analysis of histopathological factors influencing the risk of lymph node metastasis in early colorectal cancer. Colorectal Dis. 2013;15(7):788-797.

39. Choi JY, Jung SA, Shim KN, et al. Meta-analysis of predictive clinicopathologic factors for lymph node metastasis in patients with early colorectal carcinoma. J Korean Med Sci. 2015;30(4):398-406.

40. Kitajima K, Fujimori T, Fujii S, et al. Correlations between lymph node metastasis and depth of submucosal invasion in submucosal invasive colorectal carcinoma: a Japanese collaborative study. J Gastroenterol. 2004;39(6):534-543.

41. Tanaka S, Haruma K, Teixeira CR, et al. Endoscopic treatment of submucosal invasive colorectal carcinoma with special reference to risk factors for lymph node metastasis. $J$ Gastroenterol. 1995;30(6):710-717.

42. Yasuda K, Inomata M, Shiromizu A, Shiraishi N, Higashi H, Kitano S. Risk factors for occult lymph node metastasis of colorectal cancer invading the submucosa and indications for endoscopic mucosal resection. Dis Colon Rectum. 2007;50(9):1370-1376.

43. Tominaga K, Nakanishi Y, Nimura S, Yoshimura K, Sakai Y, Shimoda T. Predictive histopathologic factors for lymph node metastasis in patients with nonpedunculated submucosal invasive colorectal carcinoma. Dis Colon Rectum. 2005;48(1):92-100.

44. Belderbos TDG, van Erning FN, de Hingh IHJT, van Oijen MGH, Lemmens VEPP, Siersema PD. Long-term recurrence-free survival after standard endoscopic resection versus surgical resection of submucosal invasive colorectal cancer: a population-based study. Clin Gastroenterol Hepatol. 2017;15(3):403-411.e1.

45. Yoshii S, Nojima M, Nosho K, et al. Factors associated with risk for colorectal cancer recurrence after endoscopic resection of 1 tumors. Clin Gastroenterol Hepatol. 2014;12(2):292-302.e3.

46. Yoda Y, Ikematsu H, Matsuda T, et al. A large-scale multicenter study of long-term outcomes after endoscopic resection for submucosal invasive colorectal cancer. Endoscopy. 2013;45(9):718-724.

47. Kiriyama S, Saito Y, Yamamoto S, et al. Comparison of endoscopic submucosal dissection with laparoscopic-assisted colorectal surgery for early-stage colorectal cancer: a retrospective analysis. Endoscopy. 2012;44(11):1024-1030 
48. Saito Y, Otake Y, Sakamoto T, et al. Indications for and technical aspects of colorectal endoscopic submucosal dissection. Gut Liver. 2013;7(3):263-269.

49. Nishiyama H, Isomoto H, Yamaguchi N, et al. Endoscopic submucosal dissection for laterally spreading tumors of the colorectum in 200 consecutive cases. Surg Endosc. 2010;24(11):2881-2887.

50. Yoshida N, Wakabayashi N, Kanemasa K, et al. Endoscopic submucosal dissection for colorectal tumors: technical difficulties and rate of perforation. Endoscopy. 2009;41(9):758-761.

51. Hisabe T, Nagahama T, Hirai F, Matsui T, Iwashita A. Clinical outcomes of 200 colorectal endoscopic submucosal dissections. Dig Endosc. 2012;24 (Suppl 1):105-109.

52. Lee E-J, Lee JB, Lee SH, et al. Endoscopic submucosal dissection for colorectal tumors- $-1,000$ colorectal ESD cases: one specialized institute's experiences. Surg Endosc. 2013;27(1):31-39.

53. Fujishiro M, Yahagi N, Kakushima N, et al. Outcomes of endoscopic submucosal dissection for colorectal epithelial neoplasms in 200 consecutive cases. Clin Gastroenterol Hepatol. 2007;5(6):678-683; quiz 645 .

54. Tanaka S, Toyonaga T, Morita Y, et al. Feasibility and safety of endoscopic submucosal dissection for large colorectal tumors. Surg Laparosc Endosc Percutan Tech. 2015;25(3):223-228.

55. Hayashi N, Tanaka S, Nishiyama S, et al. Predictors of incomplete resection and perforation associated with endoscopic submucosal dissection for colorectal tumors. Gastrointest Endosc. 2014;79(3):427-435.

56. Patel N, Patel K, Ashrafian H, Athanasiou T, Darzi A, Teare J. Colorectal endoscopic submucosal dissection: Systematic review of mid-term clinical outcomes. Dig Endosc. 2016;28(4):405-416.

57. Tanaka S, Tamegai Y, Tsuda S, Saito Y, Yahagi N, Yamano HO. Multicenter questionnaire survey on the current situation of colorectal endoscopic submucosal dissection in Japan. Dig Endosc. 2010;22 (Suppl 1): S2-S8.

58. Tajika M, Niwa Y, Bhatia V, et al. Comparison of endoscopic submucosal dissection and endoscopic mucosal resection for large colorectal tumors. Eur J Gastroenterol Hepatol. 2011;23(11):1042-1049.

59. Wang S, Gao S, Yang W, Guo S, Li Y. Endoscopic submucosal dissection versus local excision for early rectal cancer: a systematic review and meta-analysis. Tech Coloproctol. 2016;20(1):1-9.

60. Nakamura F, Saito Y, Sakamoto T, et al. Potential perioperative advantage of colorectal endoscopic submucosal dissection versus laparoscopy-assisted colectomy. Surg Endosc. 2015;29(3):596-606.

61. Tomiki Y, Kawai M, Takehara K, et al. Clinical pathway to discharge 3 days after colorectal endoscopic submucosal dissection. Dig Endosc. 2015;27(6):679-686.

62. Moss A, Williams SJ, Hourigan LF, et al. Long-term adenoma recurrence following wide-field endoscopic mucosal resection (WF-EMR) for advanced colonic mucosal neoplasia is infrequent: results and risk factors in 1000 cases from the Australian Colonic EMR (ACE) study. Gut. 2015;64(1):57-65.

63. Ferreira J, Akerman P. Colorectal endoscopic submucosal dissection: past, present, and factors impacting future dissemination. Clin Colon Rectal Surg. 2015;28(3):146-151.

64. Sakamoto T, Saito Y, Fukunaga S, Nakajima T, Matsuda T. Learning curve associated with colorectal endoscopic submucosal dissection for endoscopists experienced in gastric endoscopic submucosal dissection. Dis Colon Rectum. 2011;54(10):1307-1312.

65. Niimi K, Fujishiro M, Goto O, Kodashima S, Koike K. Safety and efficacy of colorectal endoscopic submucosal dissection by the trainee endoscopists. Dig Endosc. 2012;24 (Suppl 1):154-158.

66. Ohata K, Ito T, Chiba H, Tsuji Y, Matsuhashi N. Effective training system in colorectal endoscopic submucosal dissection. Dig Endosc. 2012;24 (Suppl 1):84-89.

67. Rahmi G, Hotayt B, Chaussade S, et al. Endoscopic submucosal dissection for superficial rectal tumors: prospective evaluation in France. Endoscopy. 2014;46(8):670-676.
68. Coda S, Trentino P, Antonellis F, et al. A Western single-center experience with endoscopic submucosal dissection for early gastrointestinal cancers. Gastric Cancer. 2010;13(4):258-263.

69. Sauer M, Hildenbrand R, Oyama T, Sido B, Yahagi N, Dumoulin FL. Endoscopic submucosal dissection for flat or sessile colorectal neoplasia $>20 \mathrm{~mm}$ : A European single-center series of 182 cases. Endosc Int Open. 2016;4(8):E895-E900.

70. Probst A, Ebigbo A, Märkl B, et al. Endoscopic submucosal dissection for early rectal neoplasia: experience from a European center. Endoscopy. 2017;49(3):222-232.

71. Uraoka T, Saito Y, Matsuda T, et al. Endoscopic indications for endoscopic mucosal resection of laterally spreading tumors in the colorectum. Gut. 2006;55(11):1592-1597.

72. Saito Y, Fujii T, Kondo H, et al. Endoscopic treatment for laterally spreading tumors in the colon. Endoscopy. 2001;33(8):682-686.

73. Kudo S, Tamura S, Nakajima T, Yamano H, Kusaka H, Watanabe H. Diagnosis of colorectal tumorous lesions by magnifying endoscopy. Gastrointest Endosc. 1996;44(1):8-14.

74. Kudo S, Rubio CA, Teixeira CR, Kashida H, Kogure E. Pit pattern in colorectal neoplasia: endoscopic magnifying view. Endoscopy. 2001;33(4):367-373.

75. Kato S, Fujii T, Koba I, et al. Assessment of colorectal lesions using magnifying colonoscopy and mucosal dye spraying: can significant lesions be distinguished? Endoscopy. 2001;33(4):306-310.

76. Yamada M, Saito Y, Sakamoto T, et al. Endoscopic predictors of deep submucosal invasion in colorectal laterally spreading tumors. Endoscopy. 2016;48(5):456-464.

77. Hayashi N, Tanaka S, Hewett DG, et al. Endoscopic prediction of deep submucosal invasive carcinoma: validation of the narrow-band imaging international colorectal endoscopic (NICE) classification. Gastrointest Endosc. 2013;78(4):625-632.

78. ASGE Technology Committee, Maple JT, Abu Dayyeh BK, et al. Endoscopic submucosal dissection. Gastrointest Endosc. 2015;81(6):1311-1325.

79. Uraoka T, Parra-Blanco A, Yahagi N. Colorectal endoscopic submucosal dissection: is it suitable in western countries? J Gastroenterol Hepatol. 2013;28(3):406-414.

80. Hassan C, Repici A, Sharma P, et al. Efficacy and safety of endoscopic resection of large colorectal polyps: a systematic review and metaanalysis. Gut. 2016;65(5):806-820.

81. Bourke MJ. Endoscopic resection for mucosal neoplasia: pushing the boundaries, confronting the reality. $J$ Gastroenterol Hepatol. 2011;26(11):1582-1584.

82. Rolny P. The need for surgery after endoscopic treatment of colorectal neoplasms is the most important outcome criterion. Endoscopy. 2017;49(1):80-82.

83. Haji A, Adams K, Bjarnason I, Papagrigoriadis S. High-frequency mini probe ultrasound before endoscopic resection of colorectal polyps-is it useful? Dis Colon Rectum. 2014;57(3):378-382.

84. Gall TMH, Markar SR, Jackson D, Haji A, Faiz O. Mini-probe ultrasonography for the staging of colon cancer: a systematic review and meta-analysis. Colorectal Dis. 2014;16(1):O1-O8.

85. Hurlstone DP, Brown S, Cross SS, Shorthouse AJ, Sanders DS. High magnification chromoscopic colonoscopy or high frequency $20 \mathrm{MHz}$ mini probe endoscopic ultrasound staging for early colorectal neoplasia: a comparative prospective analysis. Gut. 2005;54(11):1585-1589.

86. Saito Y, Yamada M, So E, et al. Colorectal endoscopic submucosal dissection: Technical advantages compared to endoscopic mucosal resection and minimally invasive surgery. Dig Endosc. 2014; 26 (Supp1 1):52-61.

87. Watanabe T, Itabashi M, Shimada Y, et al. Japanese Society for Cancer of the Colon and Rectum (JSCCR) Guidelines 2014 for treatment of colorectal cancer. Int J Clin Oncol. 2015;20(2):207-239.

88. Kim HG, Sethi S, Banerjee S, Friedland S. Outcomes of endoscopic treatment of second recurrences of large nonpedunculated colorectal adenomas. Surg Endosc. 2016;30(6):2457-2464. 
89. Chedgy FJQ, Bhattacharyya R, Kandiah K, Longcroft-Wheaton G, Bhandari P. Knife-assisted snare resection: a novel technique for resection of scarred polyps in the colon. Endoscopy. 2016;48(3):277-280.

90. Zhou P, Yao L, Qin X, Xu M, Zhong Y, Chen W. Endoscopic submucosal dissection for locally recurrent colorectal lesions after previous endoscopic mucosal resection. Dis Colon Rectum. 2009;52(2): 305-310.

91. Kuroki Y, Hoteya S, Mitani T, et al. Endoscopic submucosal dissection for residual/locally recurrent lesions after endoscopic therapy for colorectal tumors. J Gastroenterol Hepatol. 2010;25(11): $1747-1753$.

92. Hurlstone DP, Shorthouse AJ, Brown SR, Tiffin N, Cross SS. Salvage endoscopic submucosal dissection for residual or local recurrent intraepithelial neoplasia in the colorectum: a prospective analysis. Colorectal Dis. 2008;10(9):891-897.

93. Sakamoto T, Saito Y, Matsuda T, Fukunaga S, Nakajima T, Fujii T. Treatment strategy for recurrent or residual colorectal tumors after endoscopic resection. Surg Endosc. 2011;25(1):255-260.

94. Isomoto H, Nishiyama H, Yamaguchi N, et al. Clinicopathological factors associated with clinical outcomes of endoscopic submucosal dissection for colorectal epithelial neoplasms. Endoscopy. 2009;41(8):679-683.

95. Sato K, Ito S, Kitagawa T, et al. Factors affecting the technical difficulty and clinical outcome of endoscopic submucosal dissection for colorectal tumors. Surg Endosc. 2014;28(10):2959-2965.

96. Matsumoto A, Tanaka S, Oba S, et al. Outcome of endoscopic submucosal dissection for colorectal tumors accompanied by fibrosis. Scand $J$ Gastroenterol. 2010;45(11):1329-1337.

97. Holt BA, Bassan MS, Sexton A, Williams SJ, Bourke MJ. Advanced mucosal neoplasia of the anorectal junction: endoscopic resection technique and outcomes (with videos). Gastrointest Endosc. 2014;79(1):119-126.

98. Tamaru Y, Oka S, Tanaka S, et al. Endoscopic submucosal dissection for anorectal tumor with hemorrhoids close to the dentate line: a multicenter study of Hiroshima GI Endoscopy Study Group. Surg Endosc. 2016;30(10):4425-4431.

99. Matsumoto S, Mashima H. The efficacy of endoscopic submucosal dissection for colorectal tumors extending to the dentate line. Int $J$ Colorectal Dis. 2017;32(6):831-837.

100. Tanaka S, Toyonaga T, Morita Y, et al. Feasibility and safety of endoscopic submucosal dissection for lower rectal tumors with hemorrhoids. World J Gastroenterol. 2016;22(27):6268-6275.

101. Yamamoto K, Michida T, Nishida T, Hayashi S, Naito M, Ito T. Colorectal endoscopic submucosal dissection: recent technical advances for safe and successful procedures. World J Gastrointest Endosc. 2015;7(14):1114-1128

102. Sakamoto T, Mori G, Yamada M, et al. Endoscopic submucosal dissection for colorectal neoplasms: a review. World $J$ Gastroenterol. 2014;20(43):16153-16158.

103. Shinozaki S, Hayashi Y, Lefor AK, Yamamoto H. What is the best therapeutic strategy for colonoscopy of colorectal neoplasia? Future perspectives from the East. Dig Endosc. 2016;28(3):289-295.

104. Hayashi Y, Miura Y, Yamamoto H. Pocket-creation method for the safe, reliable, and efficient endoscopic submucosal dissection of colorectal lateral spreading tumors. Dig Endosc. 2015;27(4):534-535.
105. Hayashi Y, Sunada K, Takahashi H, et al. Pocket-creation method of endoscopic submucosal dissection to achieve en bloc resection of giant colorectal subpedunculated neoplastic lesions. Endoscopy. 2014;46 (Suppl 1 UCTN):E421-E422.

106. Mavrogenis G, Hochberger J, Deprez P, Shafazand M, Coumaros D, Yamamoto K. Technological review on endoscopic submucosal dissection: available equipment, recent developments and emerging techniques. Scand J Gastroenterol. 2017;52(4):486-498.

107. Oyama T. Counter traction makes endoscopic submucosal dissection easier. Clin Endosc. 2012;45(4):375-378.

108. Tsuji K, Yoshida N, Nakanishi H, Takemura K, Yamada S, Doyama H. Recent traction methods for endoscopic submucosal dissection. World J Gastroenterol. 2016;22(26):5917-5926.

109. Suzuki S, Gotoda T, Kobayashi Y, et al. Usefulness of a traction method using dental floss and a hemoclip for gastric endoscopic submucosal dissection: a propensity score matching analysis (with videos). Gastrointest Endosc. 2016;83(2):337-346.

110. Uraoka T, Ishikawa $\mathrm{S}$, Kato J, et al. Advantages of using thin endoscope-assisted endoscopic submucosal dissection technique for large colorectal tumors. Dig Endosc. 2010;22(3):186-191.

111. Aihara H, Ryou M, Kumar N, Ryan MB, Thompson CC. A novel magnetic countertraction device for endoscopic submucosal dissection significantly reduces procedure time and minimizes technical difficulty. Endoscopy. 2014;46(5):422-425.

112. Imaeda H, Hosoe N, Ida Y, et al. Novel technique of endoscopic submucosal dissection by using external forceps for early rectal cancer (with videos). Gastrointest Endosc. 2012;75(6):1253-1257.

113. Tanaka S, Terasaki M, Hayashi N, Oka S, Chayama K. Warning for unprincipled colorectal endoscopic submucosal dissection: accurate diagnosis and reasonable treatment strategy. Dig Endosc. 2013;25(2):107-116.

114. Le Roy F, Manfredi S, Hamonic S, et al. Frequency of and risk factors for the surgical resection of nonmalignant colorectal polyps: a population-based study. Endoscopy. 2016;48(3):263-270.

115. Berr F, Ponchon T, Neureiter D, et al. Experimental endoscopic submucosal dissection training in a porcine model: learning experience of skilled Western endoscopists. Dig Endosc. 2011;23(4):281-289.

116. Draganov PV, Chang M, Coman RM, Wagh MS, An Q, Gotoda T. Role of observation of live cases done by Japanese experts in the acquisition of ESD skills by a western endoscopist. World J Gastroenterol. 2014;20(16):4675-4680.

117. Oyama T, Yahagi N, Ponchon T, Kiesslich T, Berr F. How to establish endoscopic submucosal dissection in Western countries. World $J$ Gastroenterol. 2015;21(40):11209-11220.

118. Spychalski M, Dziki A. Safe and efficient colorectal endoscopic submucosal dissection in European settings: is successful implementation of the procedure possible? Dig Endosc. 2015;27(3):368-373.

119. Yang D-H, Jeong GH, Song Y, et al. The feasibility of performing colorectal endoscopic submucosal dissection without previous experience in performing gastric endoscopic submucosal dissection. Dig Dis Sci. 2015;60(11):3431-3441.

120. Shiga H, Kuroha M, Endo K, et al. Colorectal endoscopic submucosal dissection (ESD) performed by experienced endoscopists with limited experience in gastric ESD. Int $J$ Colorectal Dis. 2015;30(12):1645-1652.

\section{Clinical and Experimental Gastroenterology}

\section{Publish your work in this journal}

Clinical and Experimental Gastroenterology is an international, peerreviewed, open access, online journal publishing original research, reports, editorials, reviews and commentaries on all aspects of gastroenterology in the clinic and laboratory. This journal is included on PubMed. The manuscript management system is completely online

\section{Dovepress}

and includes a very quick and fair peer-review system, which is all easy to use. Visit http://www.dovepress.com/testimonials.php to read real quotes from published authors. 